\section{Clinical phenotypes and molecular characterisation of three patients with Ehlers-Danlos syndrome type VII}

EDITOR-The Ehlers-Danlos syndrome (EDS) is a diverse group of heritable connective tissue disorders whose primary clinical features include soft, hyperextensible skin, dystrophic scarring, easy bruising, and joint hypermobility. ${ }^{1}$ An initial classification defined 10 distinct types of EDS,${ }^{1}$ but with recent advances in our understanding of the molecular pathology a revised nosology with six types has been proposed. ${ }^{2}$ In the original classification, EDS type VII, a subgroup characterised by extreme joint laxity, was divided into three subtypes, EDS VIIA, VIIB, and VIIC. ${ }^{1}$ In the revised nosology EDS VIIA and B are combined as the arthrochalasia type of EDS ${ }^{2}$ and, because of significant differences in the clinical phenotypes and molecular pathology, are separated from EDS VIIC, which is now called the dermatosparaxis type of EDS. EDS VIIA and VIIB (arthrochalasia type) are autosomal dominant disorders and the patients present with bilateral congenital hip dislocations, extreme multiple joint laxity, and recurrent subluxations of both large and small joints. Thoracolumbar scoliosis, short stature, and muscle hypotonia are common features. EDS VIIC (dermatosparaxis type) is a rare autosomal recessive form and the patients present with generally lax, extremely fragile, redundant skin analogous to the animal disease dermatosparaxis, ${ }^{34}$ umbilical or inguinal hernias, blue sclerae, numerous palmar creases, and micrognathia. They develop joint laxity but without subluxations.

Type I collagen is the major structural protein of the connective tissues affected in EDS VII. It is a heterotrimeric protein containing two $\alpha 1$ (I) chains and one $\alpha 2$ (I) chain, the products of the two genes COL1A1 and $C O L 1 A 2$. It is initially synthesised as a precursor protein having additional peptide sequences (propeptides) at both ends of the molecule; these must be removed by specific proteolytic enzymes to generate the mature protein. ${ }^{5}$ Fail- ure to cleave the amino-terminal propeptides and subsequent lack of intermolecular cross linking produces the EDS VII phenotypes. In EDS VIIA and B (arthrochalasia type), mutations in the COL1A1 or COL1A2 genes respectively result in the loss of exon 6 sequences from the mature mRNA. In both genes, exon 6 encodes a short junctional peptide sequence between a small triple helical segment in the N-propeptide and the major triple helical domain of the protein. It contains the procollagen $\mathrm{N}$-proteinase cleavage site and a lysine residue involved in intermolecular cross linking. In EDS VIIC (dermatosparaxis type), the enzyme that performs the processing, procollagen $\mathrm{N}$-proteinase, is defective. ${ }^{3}{ }^{4} 6$

We have investigated three cases of EDS VII and report the clinical phenotypes and molecular characterisation. The first has a unique de novo genomic deletion resulting in the loss of two exons (5 and 6) from COL1A1 transcripts, the second has a heterozygous mutation of the 3' acceptor splice signal of IVS5 leading to alternative splicing of COL1A1 exon 6, and the third is heterozygous for a $\mathrm{G}^{+1} \rightarrow \mathrm{T}$ in the donor splice site of COL1A2 IVS6 and has a mother who is mosaic for the mutation.

Proband 1, a girl, was born at 38 weeks' gestation by caesarian section for breech position after an uncomplicated pregnancy. Birth weight was $2790 \mathrm{~g}$ (25th centile). At birth, a right femoral fracture, bilateral dislocation of the hips, extreme joint hypermobility (especially the knees), large anterior and posterior fontanelles, and frontal bossing were noted. The skin was normal. Soon after birth she was found to be myopic and subsequently developed keratoconus. In the first year of life, she suffered recurrent dislocations of the elbows and knees with persistent hip subluxation. Development was appropriate apart from delayed motor milestones. At 14 months of age (fig 1), height and weight were on 25 th centile and there was generalised joint laxity with particularly marked instability of the left hip. There was mild cutis laxa with a criss cross patterning of the hands and feet. The sclerae were blue and dentition normal. When re-examined at 4 years 6 months, her joints were still very hypermobile with subluxation of the radial heads and the small joints of the hands and feet. The instability of the knees and ankles precluded weight
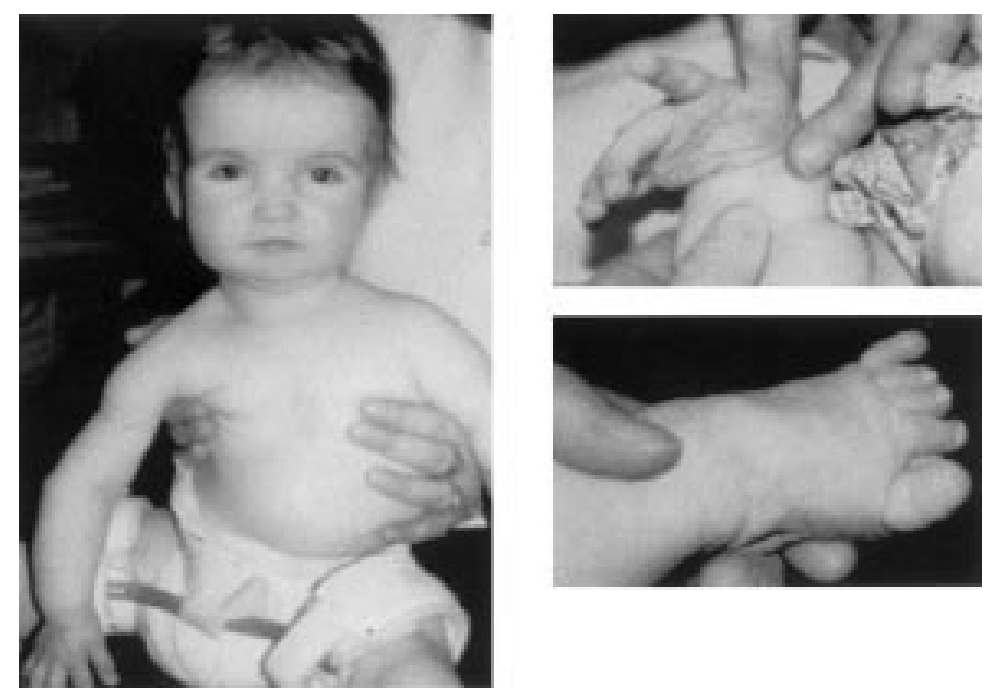

Figure 1 Clinical features of proband 1 showing joint laxity in the hands and feet. 

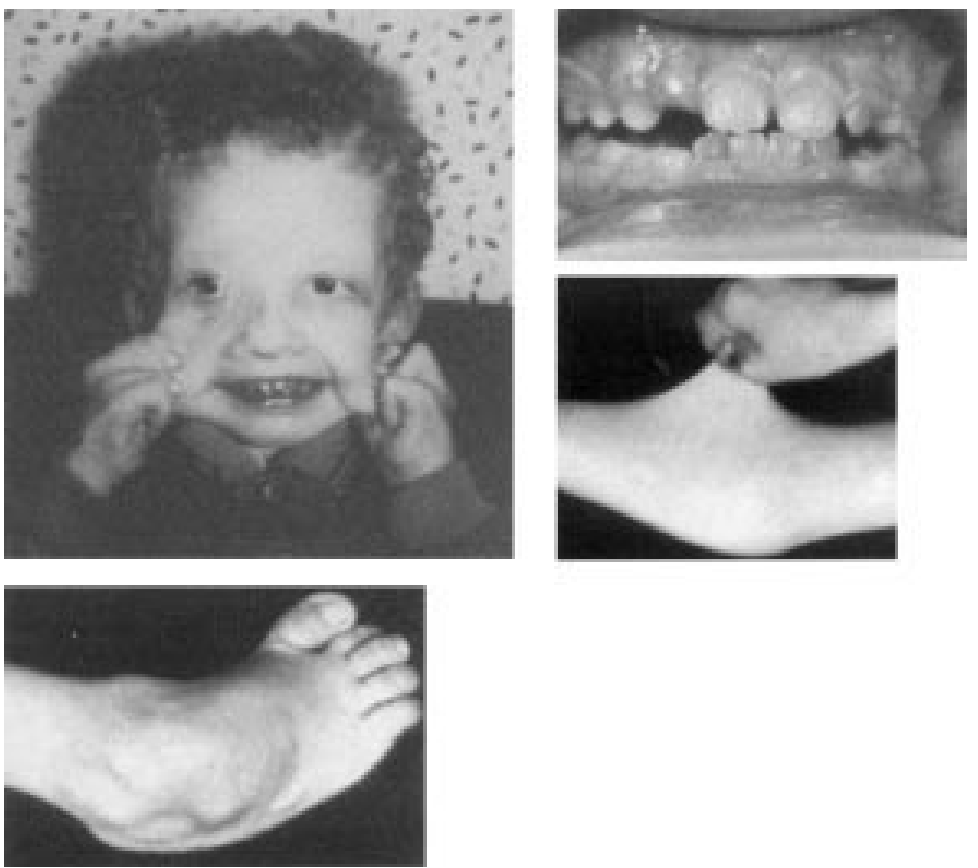

Figure 2 Clinical features of proband 2 showing joint laxity, dentinogenesis imperfecta, and skin hyperextensibility.

bearing and necessitated ambulation by means of "bottom shuffling" or wheelchair. The skin had developed easy abrasion and tearing but healed readily with normal scar formation. The proband was the youngest of three sibs born to non-consanguineous, white parents. The older sibs were clinically unaffected twins. The mother had mild joint hypermobility but no other stigmata of EDS. A skin biopsy was obtained from the proband. Blood samples were obtained from the parents.

Proband 2 was a boy born after 36 weeks of his mother's first pregnancy weighing $2900 \mathrm{~g}$. Both feet were rotated outwards to an angle of $180^{\circ}$ because of bilateral hip dislocations. These were treated initially with plaster casts. When he was 1 year old, an attempt at surgical stabilisation failed. At 1 week old he suffered a spontaneous fracture of his right femur during bathing and at the age of 7 years he fractured his skull in a minor fall; subsequent skull $x$ rays showed multiple wormian bones. He has also suffered a crush fracture of one thumb. Clinical examination at 9 years 6 months showed a small child $(<3$ rd centile for height and weight) who was facially dysmorphic with frontal bossing, hypertelorism, epicanthic folds, and blue sclerae (fig 2). His teeth showed generalised dentinogenesis imperfecta. The skin was generally lax, redundant, and hyperextensible but was without scarring or bruising. There was a prominent criss cross patterning on both palms and soles. Both large and small joints were extremely lax. A progressive, severe kyphoscoliosis, convex to the right, had developed from the age of 3 months. He was confined to a wheelchair because the severe laxity of the hips and knees made them unable to bear weight. He was intellectually advanced and talked before he was 1 year old. He has a clinically normal maternal half sister but no full sibs. His father has ankylosing spondylitis but otherwise there was no family history of connective tissue disorders. A skin sample was obtained from the child for molecular and electron microscopy studies.

Proband 3 was a boy who presented with a history of chronic instability and recurrent dislocations of both knees and elbows, which were sufficiently severe to require heavy
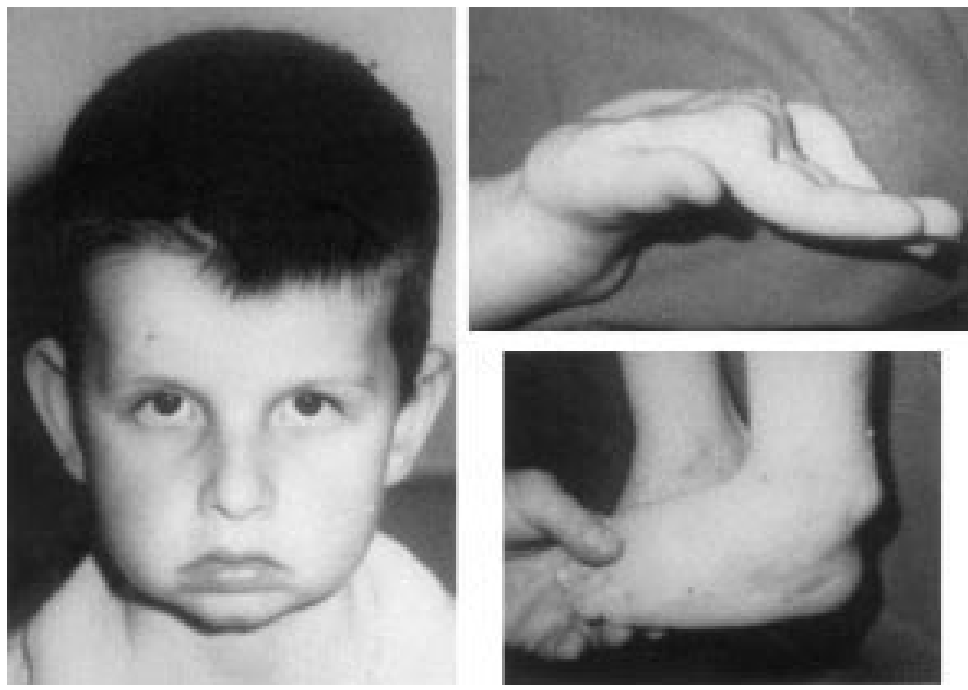

Figure 3 Clinical features of proband 3 showing joint laxity. 


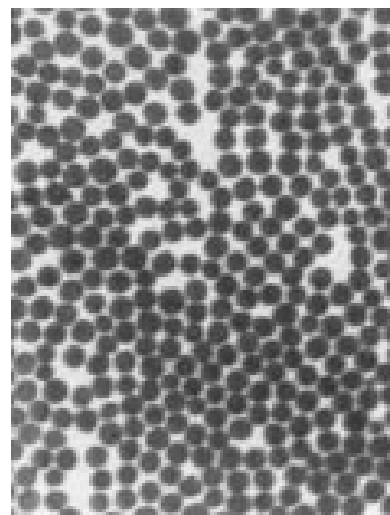

Control

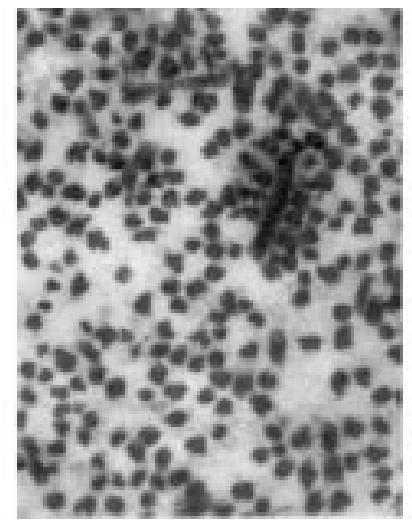

Proband 1

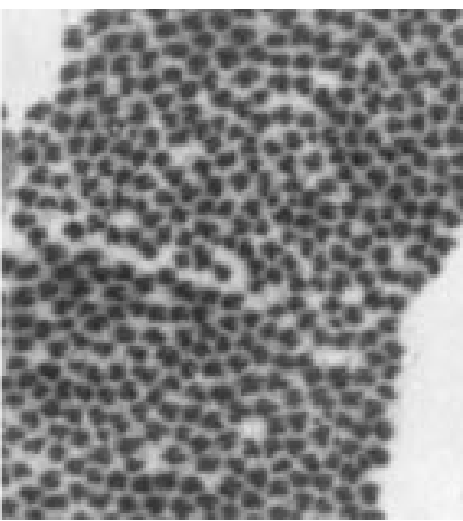

Proband 2

Figure 4 Electron micrographs of collagen fibril cross sections in skin from probands 1, 2, and a control.

external supportive harnesses but not surgical intervention. During infancy he had suffered temporary hip dislocations which had responded to splinting. He was a late walker and somewhat accident prone because of his joint laxity. In the perinatal period he had a temporary hiatus hernia. Clinical examination at 10 years of age showed a slightly dysmorphic face with frontal bossing and both face and upper chest showed mild cutis laxa. The joints were extremely hypermobile (Beighton score 9/9) with bilateral dislocations of the radial heads and excessively extensible wrists, elbows, knees, and ankles (fig 3). His feet were broad and diamond shaped with severe premature hallux valgus and pes planus on weight bearing. There was mild scarring of the forehead, chin, and knees. His father was clinically normal but his mother showed slightly increased joint mobility. Initially a sputum sample, then a blood sample were obtained from the proband but a skin biopsy was not available. Blood samples were obtained from both parents.

Portions of the skin samples from probands 1 and 2 were processed for transmission electron microscopy as previously described. ${ }^{7}$ Both had collagen fibres with irregular, angulated cross sections in marked contrast to the smooth, round outlines of the control fibres (fig 4).

Skin fibroblasts from probands 1 and 2 were labelled with ${ }^{14} \mathrm{C}$-proline $(1 \mu \mathrm{Ci} / \mathrm{ml}) .{ }^{7}$ Proteins were harvested from the medium by ethanol precipitation and from the cell layers by lysis in acetic acid/triton X100 at $4^{\circ} \mathrm{C}$. Medium and cell layer procollagens were converted to collagen by limited proteolysis with pepsin, trypsin, or chymotrypsin. Cells were also labelled in the presence of $0.05 \%$ dextran sulphate for 24 hours, the washed cells were then scraped into PBS, collected by centrifugation, and extracted with $0.1 \mathrm{~mol} / 1 \mathrm{NH}_{4} \mathrm{HCO}_{3} / 0.1 \%$ SDS by incubating for five minutes in a boiling water bath. Aliquots of the extracts were lyophilised for gel electrophoresis. Procollagen and collagen chains were analysed on $5 \%$ polyacrylamide gels containing $2 \mathrm{~mol} / \mathrm{l}$ urea using the tris-glycine-SDS system. ${ }^{8}$

The SDS-PAGE gels of the mercaptoethanol reduced procollagens from proband 1 showed an additional band just below the normal proa1(I) chain (fig 5A). Unreduced, the procollagens showed an extra band just below the normal $\mathrm{pN} \alpha 1$ (I) position (fig 5A). Following trypsin or pepsin digestion under standard conditions $(50 \mu \mathrm{g} / \mathrm{ml}$ enzyme, $15^{\circ} \mathrm{C}$, four hours), the proband's collagens appeared normal on gels. However, with chymotrypsin or reduced pepsin concentrations an extra band above the normal $\alpha 1$ (I) was apparent in the patient's sample but not in controls (fig 5B). This extra component migrated slightly faster than a normal $\mathrm{pN \alpha}(\mathrm{I})$ chain. Extracts of the proband's cell layer after dextran sulphate supplemented labelling showed persistent $\mathrm{pN} \alpha 1$ (I) and $\mathrm{pN} \alpha 2$ (I) chains, which were not seen in control cells (fig 5C).

The reduced procollagens of proband 2 (fig $6 \mathrm{~A}$ ) and the collagens derived by standard pepsin and trypsin digestion showed a normal profile on SDS-PAGE. However, chymotrypsin or lower concentrations of pepsin again showed a band running behind the $\alpha 1$ (I) chain (fig 6B). Labelling of post confluent cultures or with dextran sulphate showed a $\mathrm{pN} \alpha 1(\mathrm{I})$ band in the cell layer extract (fig 6C).

RNA was isolated from the fibroblast cultures of probands 1 and 2 and controls by the NP40 lysis technique $^{9}$ or by RNeasy kit (Qiagen). RT-PCR of control fibroblast RNA with primers from exon 1 and exon 8 of $C O L 1 A 1$ yielded a product of approximately $700 \mathrm{bp}$; however, the RNA from proband 1 gave only a single product of about $500 \mathrm{bp}$ (fig 7A). Although this appeared to indicate homozygosity for the shortened product, it was

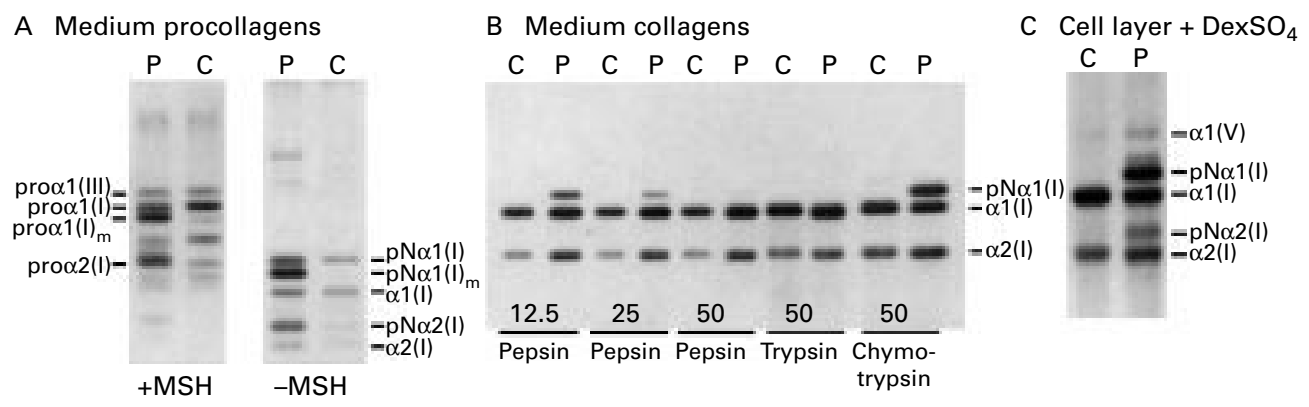

Figure 5 SDS polyacrylamide gels of collagenous proteins produced by skin fibroblasts from proband 1. (A) Patient (P) and control $(C)$ medium procollagens with $(+M S H)$ and without $(-M S H)$ reduction with mercaptoethanol. Proa $1(I))_{m}$ and $p N a 1(I)_{m}$ are the abnormal protein seen in the patient $(P)$ and not in a control $(C)$. (B) Collagens derived by limited digestion with proteolytic enzymes of patient $(P)$ and control $(C)$ medium procollagens; numbers above bars refer to enzyme concentration in $\mu \mathrm{g} / \mathrm{ml}$. (C) Cell layer extracts of control $(C)$ and patient $(P)$ cells after labelling in the presence of dextran sulphate. 
A Medium procollagens

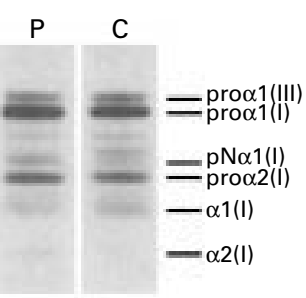

B Medium collagens

C P C C P C

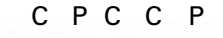

C Cell layer $+\mathrm{DexSO}_{4}$

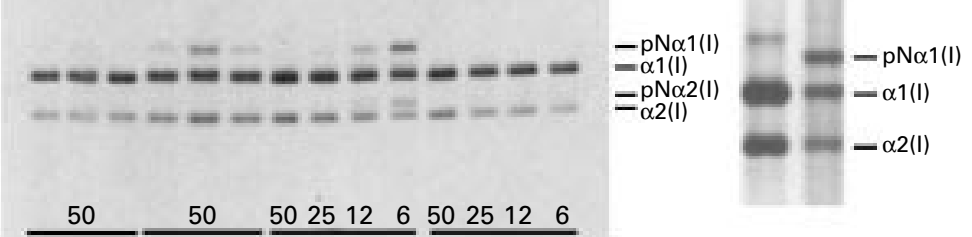

$\frac{50}{\text { Trypsin }} \frac{50}{\begin{array}{c}\text { Chymo- } \\ \text { trypsin }\end{array}} \frac{502512 \quad 6}{\text { Pepsin }} \frac{5025126}{\text { Pepsin }}$

Figure 6 SDS polyacrylamide gels of collagenous proteins produced by skin fibroblasts from proband 2. (A)

Mercaptoethanol reduced medium procollagens from patient $(P)$ and control $(C)$ cells. $(B)$ Proteolytic enzyme digests of native medium procollagens from patient $(P)$ and control $(C)$; numbers above bars indicate enzyme concentrations in

$\mu \mathrm{g} / \mathrm{ml}$. (C) Cell layer extracts of control $(C)$ and patient $(P)$ cells after dextran sulphate supplemented cell labelling.

found that mixing patient and control RTs in equal amounts also yielded only low molecular weight product (fig 7A, lane $\mathrm{P}+\mathrm{C}$ ), indicating that the smaller fragment was being selectively amplified. Comparing the sequences of a control $700 \mathrm{bp}$ fragment and the patient's $500 \mathrm{bp}$ product cloned into M13mp18 and M13mp19 identified a deletion of the $174 \mathrm{bp}$ comprising exons 5 and 6 of COL1A1 (fig 7B).

Genomic DNA was isolated from fibroblasts of proband 1 and blood from both her parents. Amplification of the proband's DNA from exon 3 to exon 8 of COL1A1 yielded an $800 \mathrm{bp}$ fragment as the only significant product, whereas the control and parental DNA gave a single band of approximately $1.6 \mathrm{~kb}$ (fig $8 \mathrm{~A}$ ). The patient's fragment was sequenced directly and also after cloning into M13 vectors (fig $8 \mathrm{~B}$ ). The sequence when compared to the published genomic sequence of exons 1-25 of COL1A1 (GenBank Accession No M20789) was in agreement through exon 4 and intron 4 and for the first 22 bp of exon 5 , but then a $T$ insertion was followed by a deletion of $883 \mathrm{bp}$ to the ninth base of intron 6. Amplification of the proband's genomic DNA with primers from intron 5 (within the deleted region) and intron 7 of COL $1 A 1$ yielded a product of normal size with normal exon 6 splice junction sequences, indicating that a normal allele was also present (data not shown).

The RT-PCR of proband 2's RNA from exon 1 to exon 8 of COL1A1 yielded multiple products (fig 9A). There was one fragment of normal size, another slightly smaller, and a third, apparently minor, product was considerably smaller than normal. There were also several higher molecular weight bands which could be attributed to heteroduplexes. Cloning and sequencing of the various fragments identified three sequences (fig 9B); one corresponded to the normal sequence, the second to a deletion of the first $15 \mathrm{bp}$ of exon 6 , and the third was missing all 72 bp of exon 6 of COL1A1.

Genomic DNA was isolated from proband 2's fibroblasts and amplified from intron 5 to intron 7 of COL1A1. This yielded a single, normal sized product. Direct sequencing (fig 10A) showed heterozygosity for a $\mathrm{G}^{-1} \rightarrow$ A substitution at the $3^{\prime}$ end of intron 5 which disrupted the obligatory -AG- of the splice acceptor site. The mutation eliminated an $\mathrm{XbaI}$ restriction site and the loss of this site in the proband's DNA confirmed the presence of the mutation (fig 10B).

Only genomic DNA was available from proband 3 and his parents. In the absence of any previous indication of the nature of his mutation, both COL1A1 and COL1A2 genes were examined. PCR amplification with primers from intron 5 and intron 7 of COL1A1 yielded a single product with a normal sequence. Amplification between introns 5 and 6 of COL1A2 gave a normal sized product whose sequence showed heterozygosity for a $\mathrm{G}^{+1} \rightarrow \mathrm{T}$ transversion in the IVS6 donor splice site (fig 11A). Allele specific oligonucleotides (ASOs) were hybridised to Southern blotted amplified genomic DNA from the patient, both parents, and several controls. All samples gave a strong signal with the wild type ASO; the mutant ASO gave a strong signal for the proband and a weak signal for his mother (not
A

B

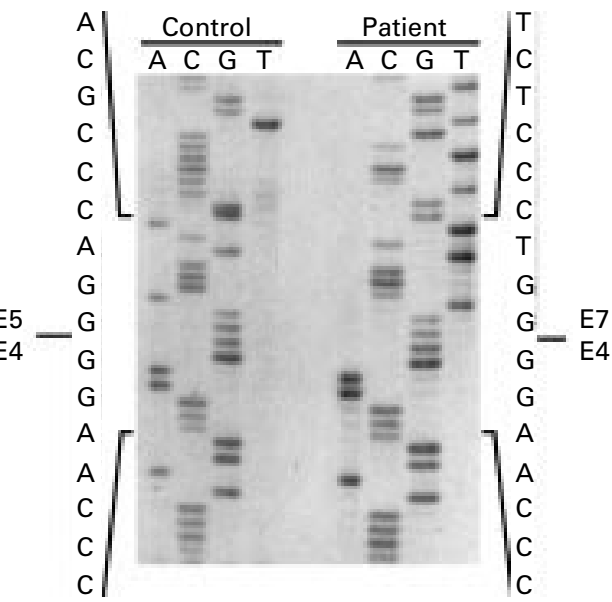

Figure 7 RT-PCR of proband 1. (A) $1.25 \%$ agarose gel of RT-PCR products from patient $(P)$, control $(C)$, and mixed patient and control $(P+C) R T s$. $L$ is a $1 \mathrm{~kb}$ ladder size marker. (B) Sequence of cloned cDNA from patient and control. 
A

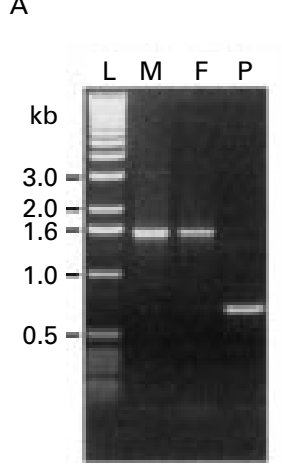

B

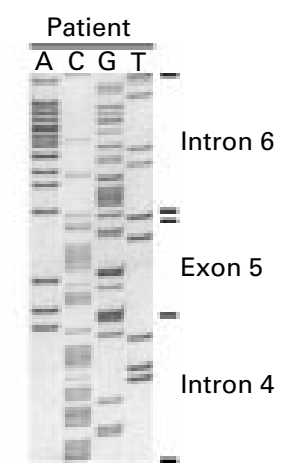

ccceggeccegccetctcccctgcagGGACCCGCAGGCCCC intron 4 I exon 5

CCTGGCC Tgcagggggagcatggatgacagaagagagaatgggtat । $1+9$ intron 6

Figure 8 PCR amplification of genomic DNA from proband 1 and her parents. (A) 1\% agarose gel of PCR products from patient $(P)$, her mother $(M)$, and father $(F) ; L$ is a 1 kb ladder. (B) Sequence of cloned genomic PCR fragment from patient.

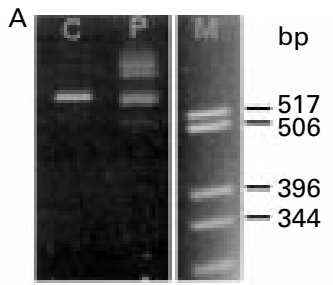

B

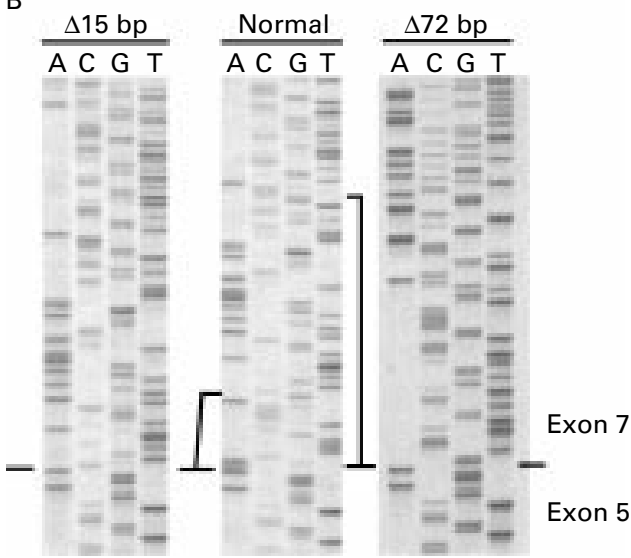

Figure 9 RT-PCR of proband 2. (A) agarose gel of patient $(P)$ and control (C) RT-PCR fragments; $M$ is 1 kb ladder. (B) Sequence of cloned $P C R$ fragments from patients.

shown) suggesting that she may be a low level mosaic. For confirmation of the mutation, specific antisense ARMS primers were designed: Wt-ARMS 5'GCTAAGATAAACAGATAAGCAAAC-3', Mu-ARMS 5'-GCTAAGATAAACAGATAAGCACAA-3' with mismatches $3 \mathrm{bp}$ from the $3^{\prime}$ end (underlined) to enhance amplification specificity under optimised conditions. These were coupled with the COL1A2 intron 5 primer for PCR amplification of genomic DNA and the products analysed on polyacrylamide gels. All samples gave a good signal with the normal (Wt-ARMS) primer combination. Using the mutant (Mu-ARMS) primer pair, the patient's DNA gave a strong signal, the mother's DNA again gave a weak signal, while the father's and all control DNA was negative (fig 11B), confirming the mother was a somatic mosaic.
All three patients show the cardinal clinical features of autosomal dominant EDS VII (arthrochalasia type). The dentinogenesis imperfecta in proband 2 is a particularly unusual feature as this has not been reported previously in EDS VII, although it is a well known characteristic of osteogenesis imperfecta. Probands 1 and 2 clearly have the more severe clinical phenotypes. This is consistent with them having mutations in $C O L 1 A 1$ for, as a consequence of the stoichiometry of the type I collagen molecule $\left[\alpha 1(\mathrm{I})_{2}\right.$ $\alpha 2(\mathrm{I})$ ], $75 \%$ of the molecules produced by heterozygous mutations in COL1A1 are abnormal compared to $50 \%$ for similar mutations in COL1A2. The electron micrographs of skin from probands 1 and 2 show an abnormal fibrillogenesis which is intermediate between the grossly abnormal hieroglyphic fibrils of patients with EDS VIIC, ${ }^{34}$ where all molecules are affected, and those of patients with COL1A2 mutations whose fibrils generally retain a smooth outline. $^{10}$

After a standard pepsin digestion procedure, proband 1 yielded apparently normal collagens on SDS gels although the procollagen profile was abnormal. Neither the procollagens nor the collagens (derived by standard pepsin digestion) of proband 2 gave any indication of an abnormality. Only a more restricted proteolysis with much lower concentrations of pepsin or with chymotrypsin showed a protein abnormality. The inclusion of low concentrations of dextran sulphate during cell labelling is known to enhance the natural processing of procollagens to collagens in vitro ${ }^{11}$ and clearly showed abnormalities in the cells from probands 1 and 2 . There were, however, subtle differences between the two for, while proband 1 accumulated both $\mathrm{pN} \alpha 1(\mathrm{I})$ and $\mathrm{pN} \alpha 2(\mathrm{I})$ chains in the cell layer, proband 2 showed only $\mathrm{pN \alpha} 1(\mathrm{I})$ chains, suggesting that in the latter the normal $\mathrm{pN} \alpha 2$ (I) chains incorporated into mutant molecules could still be cleaved by the N-propeptidase.

Proband 1 is unique among reported cases of EDS VII in that her mutation results in the loss of not just one but two exons (5 and 6) from the amino-terminus of the prod $1(\mathrm{I})$ chain. Loss of exons 5 and 6 deletes 58 amino acids from the proa 1 (I) N-propeptide including 12 of the 17 triplets of the short triple helical domain, the telopeptide (containing the procollagen peptidase cleavage site and a lysine residue involved in intermolecular cross linking), and the first triplet of the major triple helical domain. When PCR amplification of both cDNA and genomic DNA from proband 1 gave only single, deleted fragments it seemed she might be homozygous for the defect. This was not consistent with two forms of proal(I) chain observed in the patient's protein gels. The absence of any evidence of the smaller fragment in either of the parent's DNA excluded recessive inheritance and also excluded the possibility of maternal somatic mosaicism suggested by the mother's mild joint laxity. Further investigations confirmed the proband possessed one normal COL1A1 allele and indicated the mutation arose de novo in the child.

The genomic mutation in proband 2 eliminates the normal -AG- splice acceptor signal at the 3 ' end of COL1A1 intron 5 leading to alternative splicing of the mutant allele to yield two products. A minor product in which the whole of exon 6 is skipped and a major product where an in frame -AG- within exon 6 (bp 14 and 15) is used as a cryptic splice site to yield a protein missing the first five amino acids of exon 6 . Both products delete the procollagen peptidase cleavage site although the smaller deletion does retain some of the telopeptide sequences. Similar observations have been made in an unrelated patient with an identical mutation ${ }^{12}$ and with analogous COL1A2 mutations identified in two additional EDS VII patients. ${ }^{12} 13$

Since only genomic DNA was available for proband 3, sequences around exon 6 in both the COL1A1 and 
A Genomic DNA

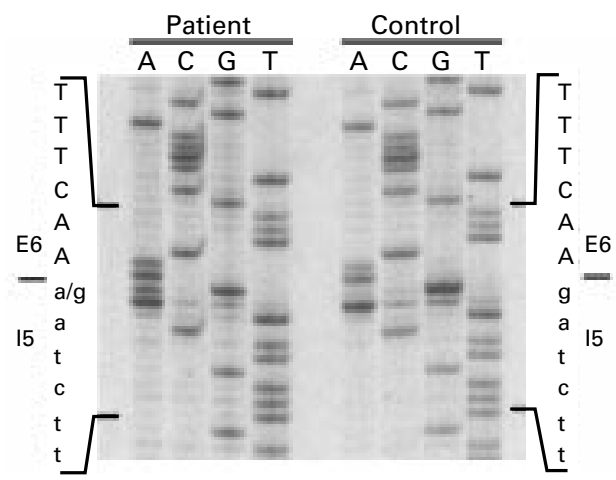

B Xbal digest

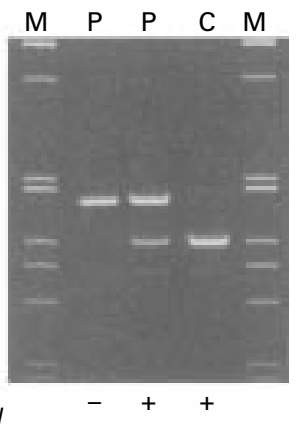

Figure 10 (A) Direct sequence of genomic DNA PCR product from proband 2 and control. (B) Polyacrylamide gel of XbaI digest of genomic DNA from patient $(P)$ and control (C); $M$ is $1 \mathrm{~kb}$ ladder.

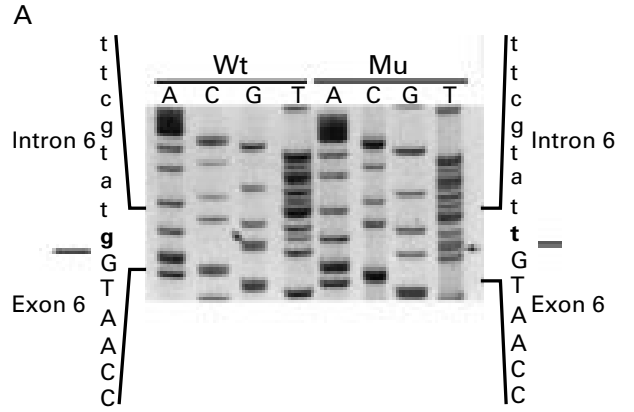

B

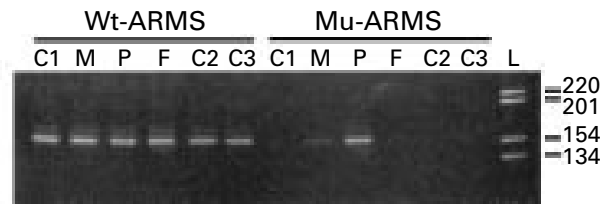

Figure 11 (A) Sequence of cloned genomic DNA PCR fragment from proband 3. (B) Polyacrylamide gel of ARMS amplimers of genomic DNA from proband $3(P)$, his mother $(M)$, father $(F)$, and controls (C1-C3) with normal (Wt-ARMS) and mutant (Mu-ARMS) specific primers. $L$ is $1 \mathrm{~kb}$ ladder.

COL1A2 genes, the sites previously identified for mutations in this disorder, were investigated. The single base substitution $\mathrm{G}^{+1} \rightarrow \mathrm{T}$ identified in the donor splice site of COL1A2 intron 6 conforms to the pattern established in previous cases of EDS VII insofar as it disrupts the obligate -GT- splice signal. This should cause skipping of exon 6 and inhibit the processing of the procollagen. ${ }^{10}{ }^{12} 16-23$ Biochemical studies of two unrelated patients with an identical mutation have confirmed this does occur. ${ }^{12}$ Allele specific oligonucleotide (ASO) hybridisation of parental DNA raised the possibility of mosaicism in the mother. ARMS primers were used to provide a more rigorous test for the mutation. In this test, the mother's DNA

Table 1 Mutations leading to Ehlers-Danlos type VII (arthrochalasia type)

\begin{tabular}{llll}
\hline Gene & Mutation & Position & Reference \\
\hline COL1A1 & $\mathrm{AG} \rightarrow \mathrm{AA}$ & 3' splice site, intron 5 & 12, this paper \\
COL1A1 & $\mathrm{G}^{-1} \rightarrow \mathrm{A}$ & 5' splice site, intron 6 & 14, 15 \\
COL1A1 & $\mathrm{G}$ enomic deletion & Exon 5 to intron 6 & This paper \\
COL1A2 & $\mathrm{AG} \rightarrow \mathrm{AC}$ & 3' splice site, intron 5 & 13 \\
COL1A2 & $\mathrm{AG} \rightarrow \mathrm{GG}$ & 3' splice site, intron 5 & 12 \\
COL1A2 & $\mathrm{G}^{-1} \rightarrow \mathrm{A}$ & 5' splice site, intron 6 & 12,16 \\
COL1A2 & $\mathrm{G}^{+1} \rightarrow \mathrm{A}$ & 5' splice site, intron 6 & $10,17-21$ \\
COL1A2 & $\mathrm{G}^{+1} \rightarrow \mathrm{T}$ & 5' splice site, intron 6 & 12 , this paper \\
COL1A2 & $\mathrm{T}^{+2} \rightarrow \mathrm{C}$ & 5' splice site, intron 6 & $21,22,23$ \\
COL1A2 & Genomic deletion & Encompassing exon 6 & 12 \\
\hline
\end{tabular}

consistently gave a weak signal with the mutant specific primers; this confirmed her mosaicism and might explain her mild joint laxity. This is the first reported instance of parental mosaicism in this disorder.

Ten different genomic mutations have now been detected in EDS VIIA and B (arthrochalasia type) patients (table 1) and all lead to the skipping or alternative splicing of exon 6 sequences and the inhibition of $\mathrm{N}$-propeptide cleavage. It is clear that $C O L 1 A 1$ mutations are underrepresented in this list despite the fact that they appear to cause a more severe clinical phenotype. Whether this disparity is because of a higher mutation rate in the $C O L 1 A 2$ gene or phenotypic variation of COL1A1 mutations or because of underdiagnosis of COL1A1 mutations by routine protein analysis is unclear. Perhaps when investigating suspected EDS VII patients, alternative approaches, such as dextran sulphate supplemented radiolabelling or more restricted proteolysis of the secreted procollagens, would prove more informative. Electron microscopy if available can also be a useful aid to diagnosis of COL1A1 mutations.

The authors gratefully acknowledge Dr E H Thompson for giving access to proband 3, Padmini Sarathachandra, Barrie Harrison, and Michelle Gaunt for the electron microscopy, and Maureen Laidlaw for maintaining the fibroblast culture.

$$
\begin{array}{r}
\text { A C NICHOLLS } \\
\text { J L SHER† } \\
\text { M J WRIGHT } \\
\text { C OLEY } \$ \\
\text { R F MUELLER } \\
\text { F M POPE }
\end{array}
$$

*MRC Connective Tissue Genetics Group, Department of Pathology,

University of Cambridge, Tennis Court Road, Cambridge CB2 1OP, UK

†Department of Orthopaedic Surgery, Cheviot E Wisbech NHS Trust,

Wansbeck General Hospital, Ashington, Northumberland NE63 97F, UK

$¥$ Northern Genetics Service, Royal Victoria Hospital, Newcastle upon

Tyne NE2 4AA UK

\Department of Clinical Genetics, Yorkshire Regional Genetics Service, St

Fames's University Hospital, Beckett Street, Leeds LS9 7TF, UK

IInstitute of Medical Genetics, University Hospital of Wales, Heath Park, Cardiff, CF4 $4 X N$, UK

Correspondence to: Dr Nicholls, alan@enicholls.freeserve.co.uk

¥Present address: Queensland Genetics Service, Royal Children’s Hospital, Herston, Queensland, Australia 4029

1 Beighton P, De Paepe A, Danks D, Finidori G, Gedde-Dahl T, Goodman R, Hall JG, Hollister DW, Horton W, McKusick VA, Opitz JM, Pope FM, Pyeritz RE, Rimoin DL, Sillence D, Spranger JW, Thompson E, Tsipouras $\mathrm{P}$, Viljoen D, Winship J, Young I. International nosology of heritable disorders of connective tissue, Berlin 1986. Am f Med Genet 1988;29:581-94.

2 Beighton P, De Paepe A, Steinmann B, Tsipouras P, Wenstrup RJ. Ehlers-Danlos syndromes: revised nosology, Villefranche 1997. Am $\mathcal{F}$ Med Genet 1998;77:31-7.

3 Nusgens BV, Verellen-Dumoulin C, Hermanns-Le T, De Paepe A, Nuytinck L, Pierard GE, Lapiere CM. Evidence for a relationship between Ehlers-Danlos type VIIC in humans and bovine dermatosparaxis. Nat Genet 1992;1:214-17. 
4 Smith LT, Wertelecki W, Milstone LM, Petty EM, Seashore MR, Braverman IM, Jenkins TG, Byers PH. Human dermatosparaxis: a form of Braverman IM, Jenkins TG, Byers PH. Human dermatosparaxis: a form of Ehlers-Danlos syndrome that results from failure to remove the aminoter-
minal propeptide of type I procollagen. Am f Hum Genet 1992;51: minal p

5 Prockop DJ, Kivirikko KI, Tuderman L, Guzman NA. Biosynthesis of collagen and its disorders. N Engl F Med 1979;301:13-23.

6 Colige A, Sieron AL, Li SW, Schwarze U, Petty E, Wertelecki W, Wilcox W, Krakow D, Cohn DH, Reardon W, Byers PH, Lapiere CM, Prockop DJ, Nusgens BV. Human Ehlers-Danlos syndrome type VIIC and bovine dermatosparaxis are caused by mutations in the procollagen-N-proteinase gene. Am f Hum Genet 1999;65:308-17.

7 Nicholls AC, Oliver JE, McCarron S, Harrison JB, Greenspan DS, Pope FM. An exon skipping mutation of a type $\mathrm{V}$ collagen gene (COL5A1) in Ehlers-Danlos syndrome. f Med Genet 1996;33:940-6.

8 Laemmli UK. Cleavage of structural proteins during the assembly of the head of bacteriophage T4. Nature 1970;227:680-5.

9 Maniatis T, Fritsch EF, Sambrook J. Molecular cloning: a laboratory manual. Cold Spring Harbour, NY: Cold Spring Harbour Laboratories Press, 1982.

10 Watson RB, Wallis GA, Holmes DF, Viljoen D, Byers PH, Kadler K. EhlersDanlos syndrome type VIIB: incomplete cleavage of abnormal type I procollagen by N-proteinase in vitro results in the formation of copolymers of collagen by $\mathrm{N}$-proteinase in vitro results in the formation of copolymers of collagen and partially cleaved pNcollagen

11 Bateman JF, Golub SB. Assessment of procollagen processing defects by fibroblasts cultured in the presence of dextran sulphate. Biochem $\mathcal{F}$ 1990;267:573-7

12 Byers PH, Duvic M, Atkinson M, Robinow M, Smith LT, Krane SM, Greally MT, Ludman M, Matalon R, Pauker S, Quanbeck D, Schwarze U. Ehlers-Danlos syndrome type VIIA and VIIB result from splice-junction mutations or genomic deletions that involve exon 6 in COL1A1 and COL1A2 genes of type I collagen. Am f Med Genet 1997;72:94-105.

13 Chiodo AA, Hockey A, Cole WG. A base substitution at the splice acceptor site of intron 5 of the COL1A2 gene activates a cryptic splice site within exon 6 and generates abnormal type I procollagen in a patient with EhlersDanlos syndrome type VII. F Biol Chem 1992;267:6361-9.
14 Weil D, D'Alessio M, Ramirez F, de Wet W, Cole WG, Chan D, Bateman JF. A base substitution in the exon of a collagen gene causes alternative splicA base substitution in the exon of a collagen gene causes alternative splicing and generates a structurally abnormal polypeptide in a

15 D'Alessio M, Ramirez F, Blumberg BD, Wirtz MK, Rao VH, Godfrey MD, Hollister DW. Characterization of a COL1A1 splicing defect in a case of Ehlers-Danlos syndrome type VII: further evidence of molecular homogeneity. Am F Hum Genet 1991;49:400-6.

16 Weil D, D'Alessio MD, Ramirez F, Steinmann B, Wirtz MK, Glanville RW, Hollister DW. Temperature dependent expression of a collagen splicing defect in the fibroblasts of a patient with Ehlers-Danlos syndrome type VII. F Biol Chem 1989;264:16804-9.

17 Weil D, D'Alessio M, Ramirez F, Eyre DR. Structural and functional characterization of a splicing mutation in the proa2(I) collagen genes of an Ehlers-Danlos type VII patient. F Biol Chem 1990;265:16007-11.

18 Vasan NS, Kuivaniemi H, Vogel BE, Minor RR, Wooton JAM, Tromp G, Weksberg R, Prockop DJ. A mutation in the proa2(I) gene (COL1A2) for type I procollagen in Ehlers-Danlos syndrome type VII: evidence suggesting that skipping of exon 6 in RNA splicing may be a common cause of the phenotype. Am f Hum Genet 1991;48:305-17.

19 Nicholls AC, Oliver J, Renouf DV, McPheat J, Palan A, Pope FM. Ehlers-Danlos syndrome type VII: a single base change that causes exon
skipping in the type I collagen $\alpha 2$ (I) chain. Hum Genet 1991;87:193-8.

20 Lehmann HW, Mundlos S, Winterpracht A, Brenner RE, Zabel B, Mulle PK. Ehlers-Danlos syndrome type VII: phenotype and genotype. Arch Derm Res 1994;286:425-8.

21 Giunta C, Superti-Furga A, Spranger S, Cole WG, Steinmann B. Ehlers-Danlos syndrome type VII: clinical features and molecular defects. F Bone foint Surgery Am 1999;81:225-38.

22 Weil D, Bernard M, Combates N, Wirtz MK, Hollister DW, Steinmann B, Ramirez F. Identification of a mutation that causes exon skipping during collagen pre-mRNA splicing in an Ehlers-Danlos syndrome variant. $\mathcal{F}$ Biol Chem 1988;263:8561-4

23 Ho KK, Kong RY, Kuffner T, Hsu LH, Ma L, Cheah KS. Further evidence that failure to cleave the amino propeptide of type I procollagen is the cause of Ehlers-Danlos syndrome type VII. Hum Mutat 1994;3:358-64. 